\title{
Analysis of the Influence of the Uncertainty of the External Environment on the Financial and Economic Sustainability of Industrial Enterprises
}

\author{
${ }^{1}$ Andrey Vladimirovich Shmidt \\ 2 Tatyana Albertovna Khudyakova \\ ${ }^{1}$ South Ural State University, Doctor of Science (Economics), Pro-rector for academic affairs \\ 454080, Lenina av., Chelyabinsk, Russia \\ 2 South Ural State University, Candidate of Science (Economics), Head of Department "Economics and Service Manadgment" \\ 454080, Lenina av., Chelyabinsk, Russia
}

\section{Doi:10.5901/mjss.2015.v6n6s2p465}

\section{Abstract}

This article analyzes the impact of the uncertainty of the external environment on the financial and economic sustainability of industrial enterprises. The analysis studied the impact of global crisis on the economic characteristics of Russian enterprises. Formulated problems caused by fluctuations in the external environment, in terms of the sustainability of the enterprise. In order to control the sustainability of the enterprise authors suggest gradation disturbances depending on the level of their occurrence: micro-, mini-, meso- and macro levels. The article substantiates the need for the development and application of probabilistic and statistical simulation models in the analysis of financial and economic sustainability of the enterprises, which is especially important during the global financial crisis.

Keywords: financial and economic sustainability, industrial enterprise, sustainable economic development, economic growth, uncertainty of the external environment.

\section{Introduction}

The modification of the geopolitical structure and the world social and economic order resulted in the augmented importance of the role of post-industrial and economically developed countries. Unfortunately, today the Russian economy falls behind the economics of the major developed countries. According to Legatum Institute (UK) data, in 2011 Russia was ranked 57 in the general listing, $34^{\text {th }}$ according to the major economic indices level and $82^{\text {nd }}$ in terms of the general welfare, while in 2012 it was ranked $66^{\text {th }}$ in the general listings. However, according to the data of the same Institute, despite the world crisis, for the last five years, Russia has reached the acceptable GDP growth rate level of $4.4 \%$, which forms a good basis for the further growth of the economy.

The Russian industry is meant to catch this gap up, so the development of the scientifically-based methods of efficient management of an enterprise is very topical and is meant to provide the basis for the accelerated industry development. However, the transition of the Russian economy towards the modern market economy has resulted in the considerable growth of uncertainty, which influences the industry environment, and determines the necessity to develop the methodological approaches to the improvement of the industrial enterprise development management based on the economic security criteria used to achieve the general competitive recovery and, consequently, the growth of returns of both the industrial enterprises and the national economy in general.

The development of the industrial enterprise development management mechanisms following the economic security criteria, aimed at the attainment of certain socio-economic and technical-and-economic indices, should include the analysis of their dynamics, while meeting the requirement of minimum expenditure, connected with the meeting of the developmental objectives. The variability of the external medium in which the industrial enterprise functions, induces the disturbances influencing the economic agent's pursuing the goal and determining the possibilities of realization of such goals as well as the necessity to work out the system of indices, providing the basis for the evaluation of the industrial enterprise management system efficiency based on the economic security criteria.

The modern world and Russian science have certain fundamental knowledge on the security of the economic systems. Such knowledge should be used as a basis for the development of the newest rational methods of management of the Russian enterprises economy based on the economic safety criteria. This fact defines the reasons for the necessity to draw the newest approaches to the evaluation of the influence the uncertainty has on the end results of the economic 
agent's activity from the point of view of its safety.

From the theoretic and methodological point of view, the most topical issues of efficient industry management are based on the economic safety criteria evaluated in the context of the production development dynamics. As the economy of the Russian Federation has generally switched to sustainable development, it is necessary for the major part of the national economy sectors to demonstrate the growth of the economic safety rate. In turn, the sustainable development of certain branches may be achieved only via the efficient sustainable functioning of the primary economic agents - the enterprises, as the industrial enterprises are the major structuring parts of economy, uniting the material, labor and financial resources to fulfill the production goals.

\section{Theoretical Framework and Literature Review}

Economic and financial stability of the industrial enterprises was investigated by I. Ansoff (1989), J. O'Shaughnessy (1976), I.A. Baev, V.I. Shiryaev, E.V. Shiryaev (2001), A.D. Sheremet (2009), V.I. Roshin (2000) I. Gurkov \& E. Avrasimova (1995), V.E. Deming (1994) and others.

A number of papers were devoted to assessing the impact of dynamic changes in the external environment on the stability of the enterprise. For such studies have been conducted I.A. Baev, V.I. Shiryaev, E.V. Shiryaev (2001), A.V. Shmidt (2011), T.A. Khudyakova (2014), A.V. Shmidt \& T.A. Khudyakova $(2006,2013)$.

However, there is a need for economic performance in the financial and economic stability of industrial enterprises in the conditions of uncertainty of the environment caused by the global economic crisis.

\section{Materials and Methods}

The Government of the Russian Federation is paying much attention to the establishment of favorable conditions for the economic agents' functioning. The regulatory and legal framework is constantly improved, the competitive goods and service market is formed, the policy is aimed at the decrease of the bank interests, the customs policy is perfected while the IT penetration rate at the enterprises is growing. However, the development of methodological approaches to the management of each primary economic agent based on its economic safety is also very important to create favorable conditions for its functioning.

The world economic crisis, which aggravated the conditions for the functioning of the Russian enterprises, caused the growth of the uncertainty in their internal and external environment has put even bigger stress on the necessity of the sustainable development of Russian enterprises to boost their competitiveness both as separate constituents of national economy, and the national economy in general.

The lack of conceptual, adequate and detailed mechanism of economic management along with the methods and instruments of economic safety management in respect to the set goals has a negative influence on the national economic development. The executive managers of the industries require serious methodological aid during the managerial decision-making. This issue is obviously topical for all of the commercial agents, and it cannot be solved without forming the mechanisms of industry sustainable development, allowing maintaining its crisis-free, stable functioning irrespective of the external disturbances of any nature.

Along with that, the lack of tools appropriate for adequate economic agent's activity management based on the economic safety maintenance became obvious due to the economic crisis the world community suffered in the end of the first decade of the XXI century, which caused considerable decrease in the volume of production, the labor market recession and the decline of the technical, economic and financial indices characterizing the activity of the enterprises and influencing their economic safety. It is also worth mentioning that the world financial crisis has extensively influenced the economic safety of the enterprises working in almost all of the national economy branches. During the crisis most of the economic indices have largely shown high variability and randomness of their nature. The drastic reduction in demand, the prices for the raw products and materials, caused by the crisis, as well as the capital drain out of the country in the end of 2008 and 2009, have resulted in the drastic reduction in the volume of production in Russia which caused the decrease of its competitive ability in general. The yield of all of the industries, as well as in construction and transport decreased by 15-20\% (Figures 1-4) in 2009 (State Statistics Service of the Russian Federation). 


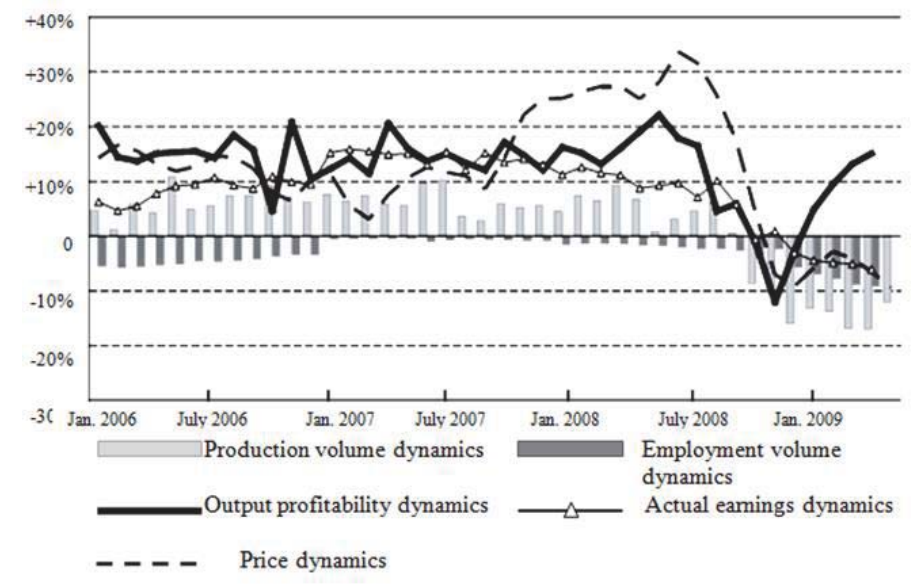

Figure 1. Industry dynamics (chain growth rate)

Source: State Statistics Service of the Russian Federation

The reduction in force in all of the economy branches were launched, the unemployment rate skyrocketed. However, despite this, the reduction in force rate was 2-3 times less than the rate of the production volume decrease, which resulted in the breach of the "golden rule of economics": the salary decrease was realized far slower, than the decrease of workforce productivity, which further aggravated the crisis of the Russian enterprises.

Moreover, during the world crisis the rates of shortfall revenue from sales of goods, services and works were several times higher than their production cost decrease rate. One of the reasons for the over-balance of the revenue decrease was the breach of the forenamed "golden rule" of economics. Another negative factor of influencing the financial and economic state of the Russian industries was the depreciation of the financial assets, as a considerable part of these assets were located both in the bank sector and the enterprises, acting in the real economy.

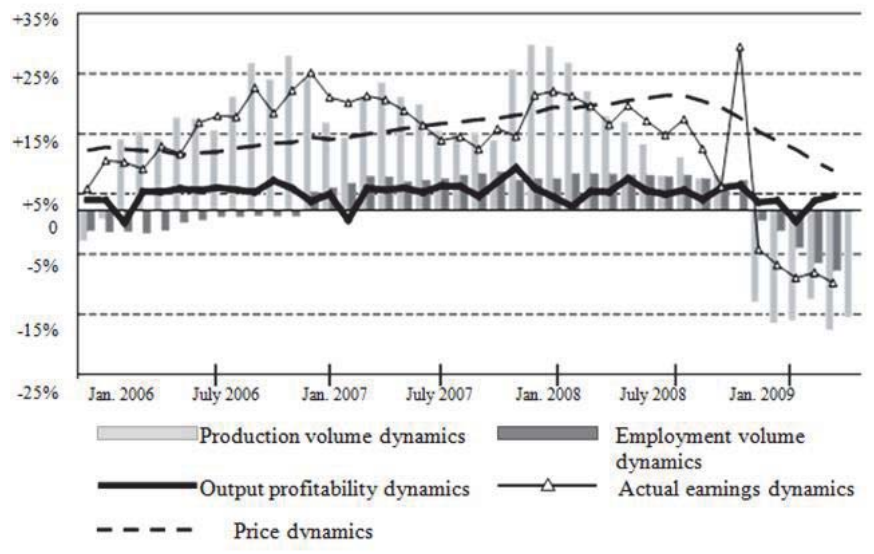

Figure 2. Construction dynamics (chain growth rate)

Source: State Statistics Service of the Russian Federation 


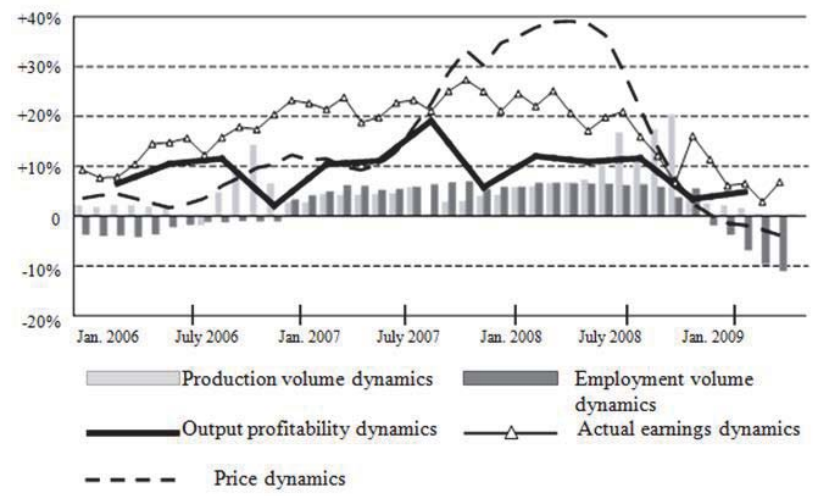

Figure 3. Dynamics of agriculture (chain growth rate)

\section{Source: State Statistics Service of the Russian Federation}

In the end of 2008 the profitability indices in almost all of the economy branches dropped down to negative. In the beginning of 2009 the profitability indices began creeping back to the positive area, however, despite this, they remained at a much lower level than they used to be before crisis.

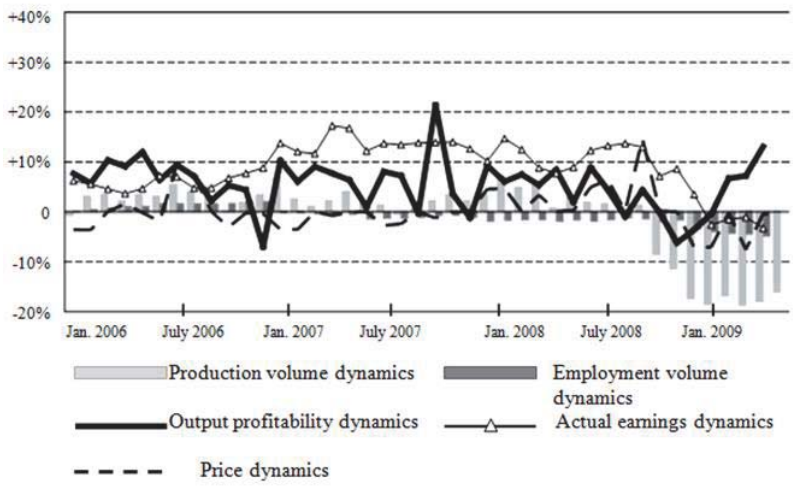

Figure 4. Dynamics of transport (chain growth rate)

Source: State Statistics Service of the Russian Federation

Moreover, the crisis resulted in the drastic decrease of the volume of investment in all of the economy branches, including industry. According to the Federal State Statistics Service in the first quarter of 2009 the rate of the investment decrease was about $15 \%$ if compared with the similar period of the previous year, and in the second quarter it was almost $20 \%$. This fact negatively influenced over the financial and economic indices of the Russian enterprises, their competitiveness and, to a huge extent, the sustainability of the enterprises and their resistance to crisis events (Figure 5).

One more disturbance for the sustainability of the Russian enterprises was that at the height of the crisis of 2009. Due to the dramatic decrease of the production volume and the demand for the products, as well as the delay in the decrease of the raw materials purchase volumes the enterprises became overstocked (Figure 6). This resulted in the deceleration the economic agents' current assets turnover, as a consequence the increase of the circulating assets of the enterprises was required. However, nowhere near all of the enterprises considered the increase of the circulating assets as a possible act. The cause for that was two-fold: first of all, the bank sphere was also affected by the crisis; secondly, the financially weakened enterprises could not bear any additional debt load. 


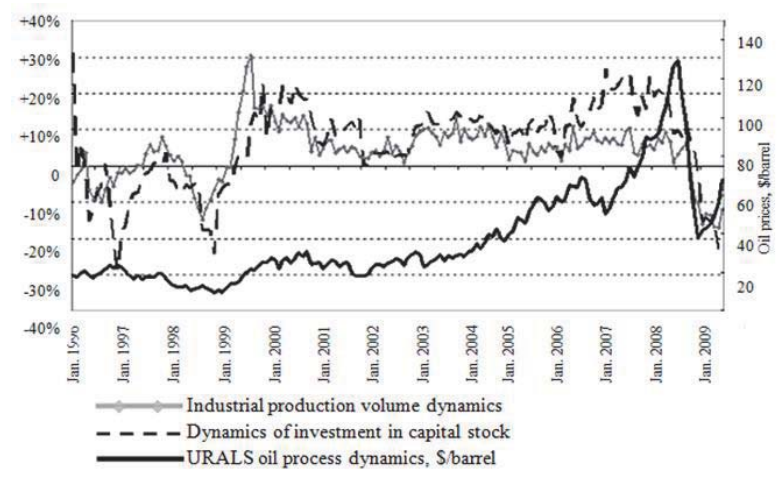

Figure 5. Chain rates of growth for the industrial production volumes, investments in capital stock, oil prices

Source: State Statistics Service of the Russian Federation

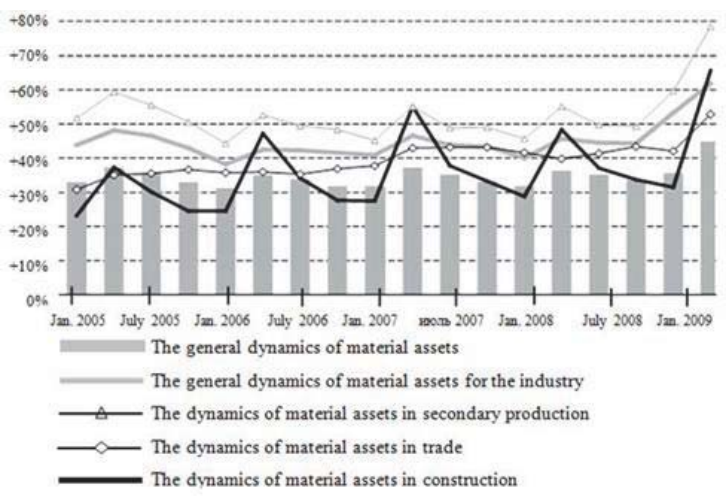

Figure 6. The relation of the circulating assets stock to the production volume at various branches of economy

Source: State Statistics Service of the Russian Federation

The complex of the fore listed negative factors dramatically decreased the financial and economic sustainability of Russian enterprises, bringing some of them to bankruptcy (Figure 7).

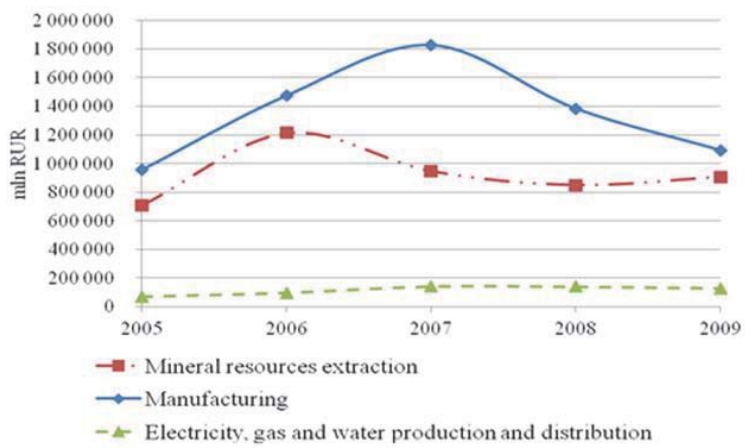

Figure 7. Balanced financial results (profit net of losses) According to the types of activity, million RUR

Source: State Statistics Service of the Russian Federation 
Thus it is worth mentioning that the variability of the environment greatly influences the variability of the final figures characterizing the economic agents' activity. The bigger the fluctuations of the indices are at the input of the economic system, the bigger they are at the output (Figures 7-9).

The problem of an economic agent bailout has to be solved in the conditions of high variability of the macro- and micro-level factors (Figure 10) (Shmidt, 2011, Shmidt \& Khudyakova, 2013).

Accounting the imoact of the disturbances on the financial, technical and economic indices characterizing the efficiency of an enterprise activity, is the prerequisite for the compilation of the enterprise management strategy aimed at the improvement of the financial and economic sustainability of an economic agent. As it has been noted before, an enterprise suffers from the influence of multiple uncertainties, which impacts a complex of various indices, characterizing the enterprise functioning efficiency.

So, the system-wide crisis is characterized by the following interdependent and complimentary problems:

- The decrease of the general competitiveness level of an enterprise;

- The decrease of the general economic efficiency of an enterprise, which is caused among other things, by the decrease of the engineering and manufacturing processes efficiency;

- The decrease of financial and economic sustainability of an enterprise;

- The decrease of the decision-making and management processes efficiency, which is caused by the rate of changes in the external environment and its high uncertainty;

- The issue of adequacy of strategic and tactical goals of the enterprise, caused by the lag in managing decision-making corrections and the rate of changes in the external environment.

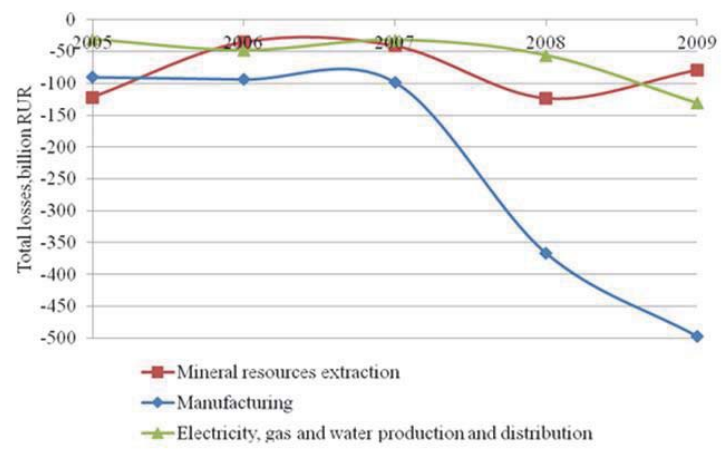

Figure 8. The total losses for the activities, in billion RUR

Source: State Statistics Service of the Russian Federation

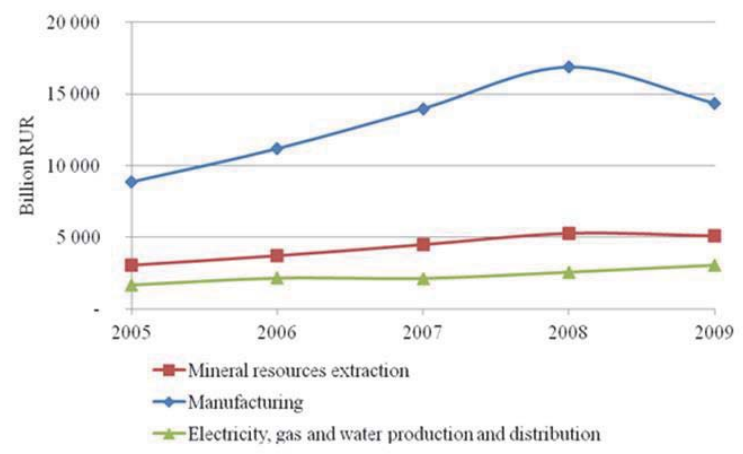

Figure 9. The volume of shipped in-house goods, works executed and services provided according to the economy branches, in billion RUR

Source: State Statistics Service of the Russian Federation 


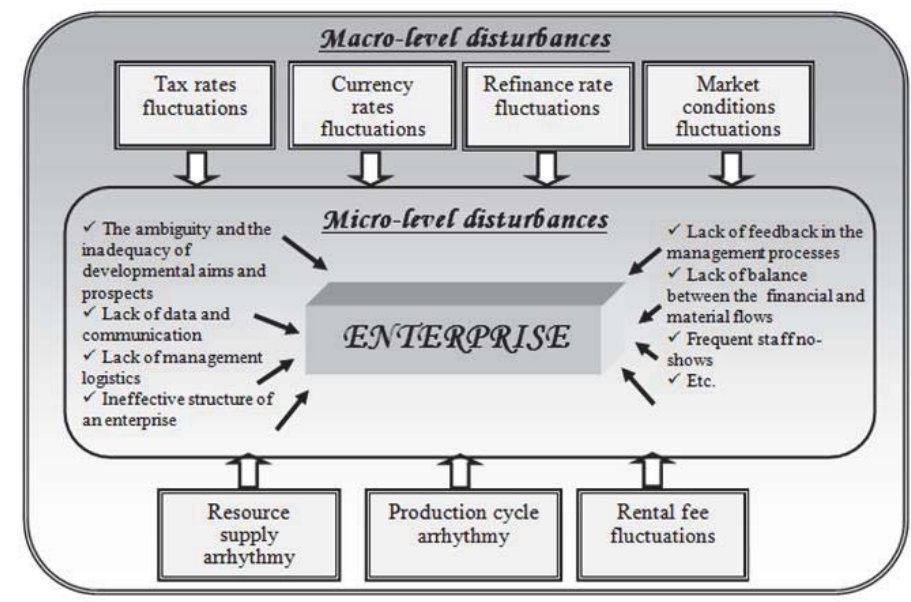

Figure 10. Factors influencing the sustainability of a micro-economic system

Source: made by the authors

The high variability and unsustainability of the external environment gives rise to the uncertainty emerging in the course of the economic system management and, consequently, causes a considerable decrease in functioning sustainability of separate enterprises, economy branches and the country economy on the whole.

The development of the managerial approaches allowing the increase in the efficiency of preventive measures, aimed at the cut down of possible financial losses due to the uncertainty and the stochastic character of the enterprise functioning, becomes more and more important.

This fact also provides the ground for the reviewal of existing approaches to the enterprise management in highly stochastic environments. The primary importance falls on the adequate evaluation of the real economic and production capacities of the Russian enterprises, established with special consideration for the uncertainty of both their internal and external environments. It is necessary to develop a range of adaptation approaches, aimed at the increase in sustainability of the economic agents against the fluctuations of their environment.

The scientific task of crucial importance consists in the identification of general patterns of an enterprise adaptation to the environmental disturbances, the search for the economic agents' management modes suitable for the variable environment as well as boosting the level of mini-economic systems resistance to the fluctuations of the input parameters.

During its resolution the enterprises should be reviewed from the point of view of their independence and selfregulation ability for the conditions characterized by the disturbances of various origins.

The disturbances may be generated at different levels of the economic agent's functioning. Relying on the classification, offered by the Dr. of Economics. E.V. Popov, one could single out four levels of an economic agent's functioning: micro-, meso-, macro- and maxi-levels (Figure 11). 


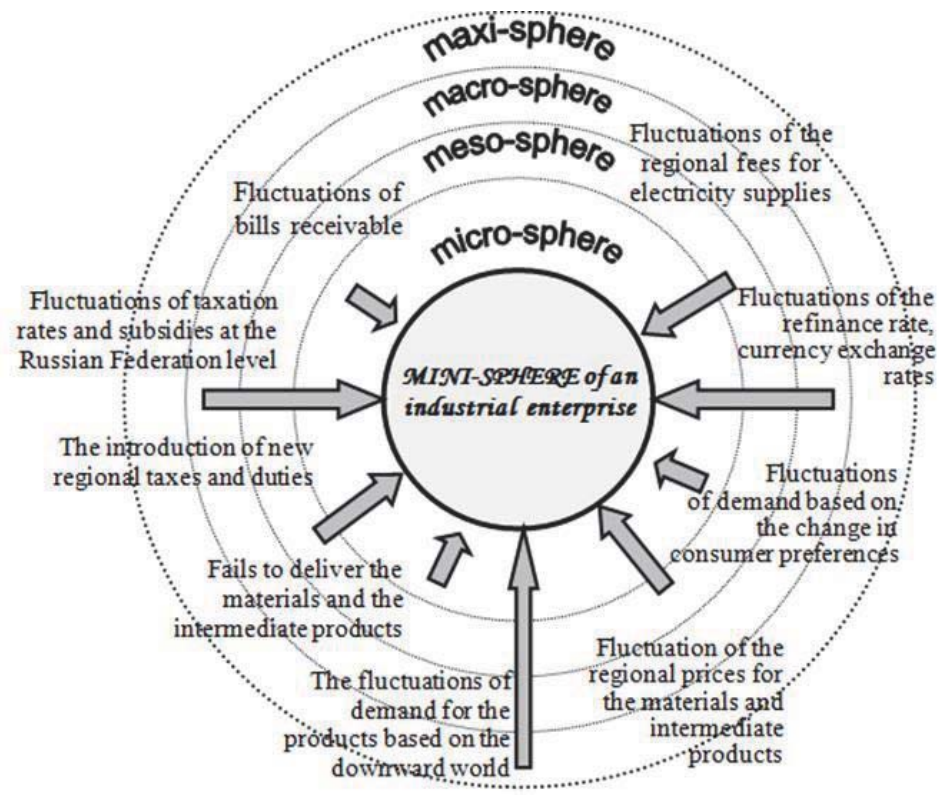

Figure 11. Maxi, macro-, meso- and micro-sphere disturbances

Source: made by the authors

Each of these levels features certain dangers for the sustainability of an enterprise. Almost all of the levels, except for the mini-level, dealing with the immediate internal environment of an enterprise, are connected with the risks based on the low precision of forecast disturbances, born in these levels. Several characteristics of the mini-economic systems are uncertain, including the number of disturbances, influencing the sustainability of the economic agent, the intensity of their impact on the financial, technical and economic characteristics of an enterprise, the expected level of this or that disturbance. All of these characteristics have sufficient influence on the financial and economic sustainability of an economic agent and may be both reversible, if after the managerial measures were taken the mini-economic system retains its equilibrium, and irreversible, when such redemption is not possible. It is clear that the irreversible changes are the most dangerous, as they bring an enterprise as far as to a new qualitative condition or, during the crisis in the socioeconomic sphere, even to bankruptcy.

It is clear that when the market fluctuations are minor, temporary or, better yet, foreseen, the mini-economic system is capable of providing a quick and adequate reaction to them by employing the standard instruments, allowing the leveling of these disturbances. In this case the following preventive or adaptation measures may be used: the cutdown of the production volume, the development of measures aimed at the cut-down of the production costs or the profit total, the diversification of products or the activities of the enterprise, etc.

In the cases when the external environment of an enterprise suffers major, unforeseen fluctuations which are not standard for the economic agent, and the system had never faced before, the management of the enterprise has no information on how the mini-economic system is going to react to this or that disturbance or what means of adaptation or prevention should be employed. The uncertainty of the conditions skyrockets, which results in the decrease of the possibility of its sustainable functioning. This results in considerable devaluation of the previous experience of the economic agent.

As in the conditions of highly-mobile operational environment the external disturbance counter-action algorithm is absent, the executive managers of an enterprise are often forced to act by means of trial and error, evaluating the correctness of the made decision post factum. However, the bigger and the more intensive the fluctuations of the operational environment are, the bigger is the danger for the enterprise to face unforeseen losses. Besides, the time left for the enterprise to adapt to the disturbances is limited. At the same time, the more frequent is the change of discrepancies, the quicker the reaction of the economic agent should be. In case the management falls back, its effect 
would be lost, at the very best, or the financial and economic condition of an enterprise may be aggravated.

Generally speaking, the variability and stochasticity of economic factors of internal and external industrial enterprises environment influence the economic cycles, which cause serious shifts in its structure.

It appears that the irreversible shifts in the structure of the external operational environment of an industrial enterprise have a nature totally different from the one of the reversible changes of its parameters. They are linked with the qualitative change in the properties of the operational environment and the economic agent's transition to a totally different condition.

The change in the structure of the operational environment of the industrial enterprises may negatively influence both the separate branches of economy, and the national economy in general, which, in turn, depends on the degree of unexpectedness and the intensity of fluctuations in socio-economic and geopolitic space.

Thus, the fluctuation of the external environment of the enterprise may be classified in the following way: singular (one-time), particular and general. The particular and general fluctuations are the consequences of the socio-economic space cyclical nature.

The financial losses, born during the long-term crisis, bring many economic agents to bankruptcy.

So, as it is shown above, the modern socio-economic conditions of the industrial enterprises operation have objective reasons for the generation of the disturbances of different origin. The variability of the external mini-economic system has a considerable influence on the efficiency of the primary branches of economics in terms of their economic and financial sustainability. This efficiency directly depends on the multitude of disturbance forms originating from different levels of the environment of the enterprise.

So, in order to be able to analyze the efficiency of an industrial enterprise functioning based on the economic sustainability criteria it is necessary to develop a clear classification of disturbances, allowing to draw up the model for the evaluation of their impact on the financial and economic characteristics of the business agent, which describes the reasons of the fluctuations, as well as the impact they have on the economic system.

Unfortunately, modern science does not possess any comprehensive tool for the adequate systematization and classification of the processes and phenomena of mini-economic systems, accounting the dynamics of these processes.

The traditional approaches to the definition of the industrial enterprises sustainability based on the analysis of the financial and economic activity provide us only with the information on the financial sustainability, while all of the indices of the mini-economic system, both the input and the output ones, are of static character. This is explained by the fact that the financial stability is based on the concrete retrospective data, picked from the financial statements of an enterprise without giving any consideration to the possible deviation of the resulting indices influenced by the disturbances of various origins.

Thus the traditional economic agents sustainability evaluation, forecast and management approaches are of little use in the highly-variable external conditions. Consequently, to develop the methodological approaches to the sustainability-based industry management it is necessary to rely on the existing approaches based on the newest research of the complex, including technical, systems sustainability.

As it has been noted above, the variable economy is characterized by the mighty fluctuations of the economic factors in macro-, meso- and mini-levels. In their core, these fluctuations are the external disturbances for the minieconomic system, which cause the transitional processes in these systems. It is the time gap of this transitional process that is particularly interesting for the study of the mini-economic system behavior and its reaction to the disturbances of various origins. The reasons for that are as follows:

1. The dynamic processes, emerging and unfolding during the transitional processes, are considerably different from the static processes and each other.

2. The change in the condition of the mini-economic systems during the transitional process very much depends on the initial condition of an enterprise.

3. In variable economy an enterprise may constantly be a part of a transitional process, unfolding under the influence of the disturbances of various origins.

4. The transitional process has a much higher possibility of causing irreversible consequences, resulting in considerable financial losses or bankruptcy of an enterprise.

\section{Conclusion}

So, one may expressly conclude that the major reasons for the emergence of the transitional processes in the minieconomic systems are the hazardous or the cyclic disturbances, influencing the major input characteristics of an industrial enterprise: the sales volume, the prices for the raw materials and constituents, the level of tax burdens, etc. 
So, when a disturbance emerges in the external environment of an enterprise (for instance when the market situation is changed), the mini-economic system hosts a transitional process, defining the uncertainty of the resulting output characteristics of the system. As it has already been noted, on the one hand, the transition of the mini-economic system from one condition to another is primarily dependent on the character and the field of application of the disturbance, on the other hand, the character of the transition process is defined by the individual characteristics of a certain enterprise.

Thus in order to study the peculiarities of the industrial enterprises functioning in the uncertainty conditions as well as in order to evaluate the extent of sustainability of an economic agent against the disturbances of different natures and the management of the mini-economic system in order to boost the possibility of sustainable functioning, it is necessary to develop an adequate economic and mathematical imitation model of an enterprise, which allows to provide the quantitative description of the impacts different factors have on the total result of the economic agent functioning. It is also necessary to establish the possibility of discrepancy between the actual and the planned results based on the imitation of the process. The model should be developed taking into account the dynamics of the system parameters.

The transitional processes unfolding in the mini-economic system are often continuous and non-periodic, which is explained by the existence of the lagging chains. It is clear, for instance, when the market trend changes enterprises are unable to provide immediate reaction to this, as the internal structure of mini-economic system has a certain inertia. So the approaches which are now being developed should be aimed at finding the ways to prevent the negative influence the disturbances have on the financial and technical and economic characteristics of the economic agent and, consequently, its general sustainability.

So, the study of the opportunities of an industrial enterprise management based on the economic sustainability criteria reviewed from the point of view of the transitional processes dynamics influenced by different disturbances is vital for the development of methodological approaches to the definition of an industrial enterprise economic sustainability, as well as forming the mechanisms and instruments, which allow the management of the processes unfolding at the enterprise aiming at improving the odds of sustainable functioning of microeconomic system.

\section{Acknowledgements}

This publication was prepared within the framework of a research project №15-32-01051 supported by the RHF.

\section{References}

Ansoff, I. (1989). The Strategic Management. Moscow: Ekonomika Publishers.

Bayev, I.A., Shiryayev, V.I., Shiryayev, E.V. (2001). The Dynamic Theory of Form: Monograph. Chelyabinsk: SUSU Publishers.

Bayev, I.A., Shmidt, A.V. (2012). Management of economic stability of the enterprise in the context of increasing its competitiveness. Bulletin of UrFU. Series: Economics and management, 3, 50-63.

Deming, V.E. (1994). Overcoming the Crisis. Tver.

Gurkov, I., Avrasimova, E. (1995). The Strategy of Survival of the Industrial Enterprises in the New Conditions. The Problems of Economics, 6, 22-30.

Khudyakova, T.A., Shmidt, A.V. (2006). Research, Evaluation and Prediction of Economic Stability of an Industrial Enterprise. Chelyabinsk: SUSU Publishers.

Khudyakova, T.A. (2014). The role of controlling during managing sustainability of industrial enterprises Innovative development of modern science: collection of articles of the International scientific-practical conference, 293-295.

O'Shaughnessy, J. (1976) Patterns of business organization. London: George Allen \& LTD.

Roshchin, V.I. (2000). The economic stability of enterprises and the implementation of their economic interests. Cheboksary.

Sheremet, A.D. (2009). The complex analysis of economic activities. Moscow: INFRA-M.

Shmidt, A.V. (2011). The Genesis of the concept of «economic stability» industrial enterprises. Business. Education. Right. Newsletter of Volgograd Institute of business, 4, 20-30.

Shmidt, A.V. (2011). The essence and the indicators of economic sustainability of the industrial enterprises. Business. Education. Right. Newsletter of Volgograd Institute of business, 3, 55-66.

Shmidt, A.V., Khudyakova, T.A. (2013). Modelling of management of development of industrial enterprises by economic criteria of the stability. Socio-economic problems of the modern Russian economy: monograph (250-282). Moscow: Economic newspaper.

State Statistics Service of the Russian Federation (2015). [Online] Available: http: // gks.ru (July 31, 2015)

System Analysis on the Brink of the XXI century: Theory and Practice: Abstracts of the international conference (1996). Moscow: Intellect. 